\title{
The analysis of aircraft fuel system ground test simulation turntable's structure
}

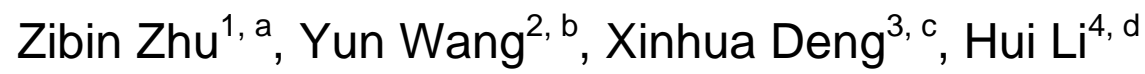 \\ ${ }^{1,2}$ Aircraft Engineering academy of NanChang HangKong University in NO.696 of FengHe South \\ Avenue, NanChang, Jiangxi Province, China \\ ${ }^{3,4}$ Hongdu Aviation Industry Corporation, New stream bridge, NanChang, Jiangxi Province, China \\ a zhuzibin2008@sina.com, ${ }^{\mathrm{b}}$ wangyun66@126.com , ${ }^{\mathrm{c}}$ ly02@hongdu.com.cn, ${ }^{\mathrm{d}}$ 14385708@qq.com
}

Keywords: aircraft flue system, ground test simulation turntable, Abaqus, structural analysis

\begin{abstract}
The aircraft fuel system simulation as an important part of aircraft design is a complex systems engineering, it is one of the experimental project to ensure the success of aircraft design. The test verifies the aircraft fuel system's correct and reasonable of design and calculation and verify that the fuel system function and reliability. The aircraft fuel system ground test turntable's frame is a key component in the test, its structural design and analysis is complex and important. Through the intensity and modal analysis of fuel system ground simulation turntable by finite element analysis software Abaqus obtain the turntable's stress and strain characteristics in the horizontal position and vertical position. And then calculate the dynamic characteristics of the turntable's six modes of natural frequencies and get the displacement images of the turntable. It provided an important theoretical basis for fuel system ground simulation turntable's optimal development and design.
\end{abstract}

\section{Introduction}

In new aircraft's design, system simulation test as an important component of the aircraft design work is a complex system engineering. Ground simulation test system can verify the correctness and accuracy of the design, and can solve some problems that the theoretically difficult to solve[1-2]. Fuel system ground simulation turntable is the key equipment in the aircraft fuel system ground simulation test, the test tank installed in the inside frame, by turning the inside and outside frames to simulate the change of the angle of flue level in the flight[3]. It is a moment of inertia of the hundreds of thousands $\mathrm{kg} \cdot \mathrm{m}^{2}$ low-speed big load equipment. Ground simulation test of the aircraft fuel system is one of the project must do to ensure the first flight is successful. The test verifies the aircraft fuel system design, calculation of the correct and reasonable and verify that the fuel system function and reliability[4]. The fuel system ground test simulation turntable structure shown in Figure 1.

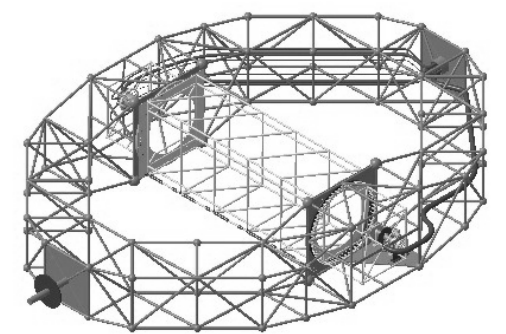

Figure 1, the fuel system ground test simulation turntable

\section{The parameters of the turntable}

The size of the turntable: $17.6 \mathrm{~m} \times 10.8 \mathrm{~m} \times 2.8 \mathrm{~m}$, the use of tube of Q345D, connected by spherical joints. The outside frame of rod 326, which with $\Phi 76 \mathrm{mmx} 4 \mathrm{~mm}$ cross-section of 272, $\Phi 83 \mathrm{mmx} 5 \mathrm{~mm}$ cross-section of $48, \Phi 102 \mathrm{mmx} 7 \mathrm{~mm}$ cross-section of $4, \Phi 402 \mathrm{mmx} 16 \mathrm{~mm}$ cross-section of 2 . Rotating frame rotation angle range: $-90^{\circ} \sim+90^{\circ}$, speed: $0 \sim \pm 20^{\circ} / \mathrm{s}$, the 
maximum angular acceleration: $10 \% \mathrm{~s}^{2}$. The test bench of the maximum load of $15 \mathrm{t}$, the overall structural strength is not less than four times safety factor.

\section{Strength Analysis}

Gravity load. Within the transmission device of the inner frame and within the working load conjunctive $15 \mathrm{t}$, taking four times safety factor, which is $60 \mathrm{t}$ calculation quality. Therefore, the inside frame pass $600 \mathrm{kN}$ load to the outside frame which through both ends of the transmission device. in horizontal position, each end passing $300 \mathrm{kN}$, in the Abaqus model, this $300 \mathrm{kN}$ load concentrated force in the form role outside frame of support plus stiffened plate 8 nodes, each node by the $37.5 \mathrm{kN}$ of concentration. In vertical position, loads mainly effect on the button of the turntable, each node is $75 \mathrm{kN}$ force, the direction is vertical downward.

Torque equivalent load. The connection between the inside and outside frame is slewing bearing, the maximum torque which the hydraulic motor pass to the inner frame is $90 \mathrm{KN} . \mathrm{m}$, then reaction to the outer frame, the equivalent of eight nodes in a radius of approximately $1000 \mathrm{~mm}$ in the outside frame, each node have $11.25 \mathrm{kN}$ of concentration.

Moment of inertia. The frame around the $\mathrm{X}$ axis to accelerate the rotation, the moment of inertia would have a maximum angular acceleration of $10 \% \mathrm{~s}^{2}$. Turntable along the $\mathrm{X}$ direction's rotational inertia is $52330 \mathrm{~kg} \cdot \mathrm{m}^{2}$. So the inertial torque:

$$
M=J \times \beta=5.233 \times 10^{4} \mathrm{~kg} . \mathrm{m}^{2} \times 0.1745 \mathrm{rad} / \mathrm{s}^{2}=9.13 \times 10^{3} \mathrm{~N} \cdot \mathrm{m}
$$

The moment of inertia add: in the center of turntable set an RP-1 point, then all the rods of the frame couple with the RP-1 point. Put (1) torque load at this point equivalent to the turntable's moment of inertia.

Deformation analysis of the time within the framework to pass outside the framework of the load to take the actual size of $150 \mathrm{kN}$ calculation, in the horizontal position, each side to pass $75 \mathrm{kN}$. Abaqus model, $75 \mathrm{kN}$ load concentration in the form of role outside the framework of the eight nodes, each node by $9.375 \mathrm{kN}$ of concentration. In vertical position $150 \mathrm{KN}$ force acting on the bottom of the bottom eight nodes, respectively, by $18.75 \mathrm{kN}$ of concentration.

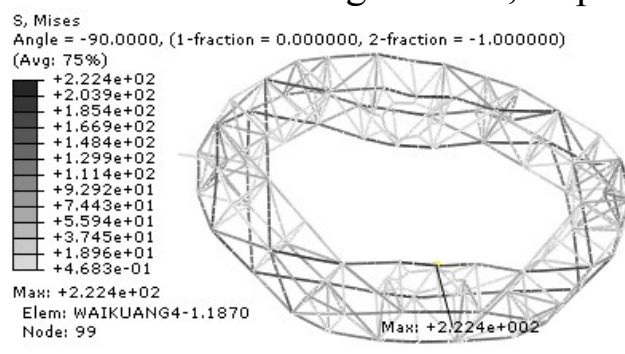

(a)

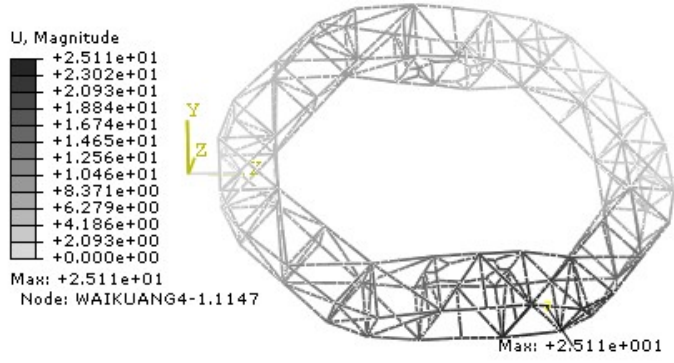

(b)

Figure 6, a) turntable's stress cloud in horizontal position b) turntable's deformation cloud in horizontal position

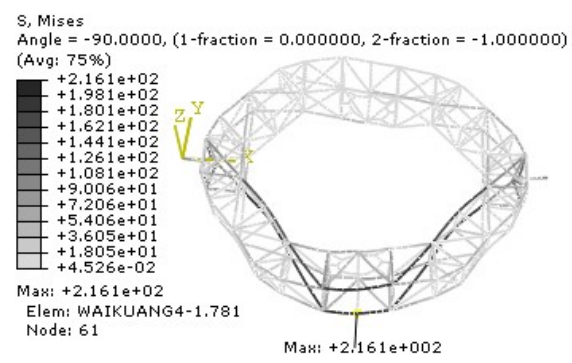

(a)

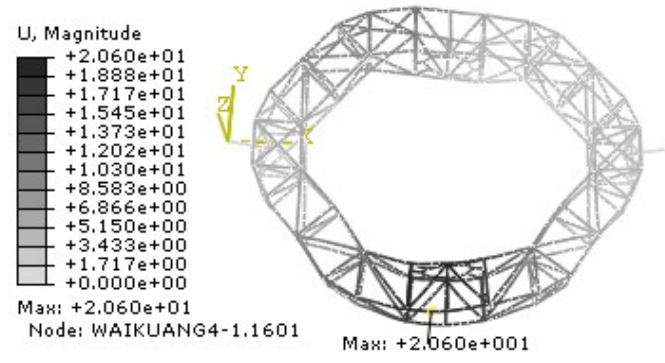

(b)

Figure 7 a) turntable's stress cloud in vertical position b) turntable's deformation cloud in vertical position

Abaqus solving turntable diagram of stress and deformation in Figure6, Figure7 shows. From the stress diagram can be seen that the central bar of the turntable framework subject to the maximum stress, maximum value 222.4MP less than 230MP the allowable stress, followed by some oblique 
bar. We can increase the turntable strength by increasing the cross-section of these rods. In the deformation diagram, Because of the inertia moment of action, leading to both sides of turntable's deformation asymmetric, and due to the inner frame on the outer frame rotating torque, resulting in each lateral deformation in the center of asymmetric turntable. The maximum deformation is $2.511 \mathrm{~cm}$, which meet the requirements.

\section{The modal analysis}

Modal analysis of the system mainly research in the undamped state vibration characteristics, mainly for the system's own natural vibration frequency and vibration mode.

Abaqus offers the Lanczos and the subspace iteration eigenvalue extraction methods. The Lanczos method is generally faster when a large number of eigenmodes is required for a system with many degrees of freedom. The subspace iteration method may be faster when only a few (less than 20) eigenmodes are needed[5]. In this analysis, we use the subspace iteration eigenvalue solver and solving for the first six eigenvalues. Table 1 lists the turntable frame the first 6 natural frequency and mode shape characteristics and there are first 6 modal diagrams as it show in Figure 9.

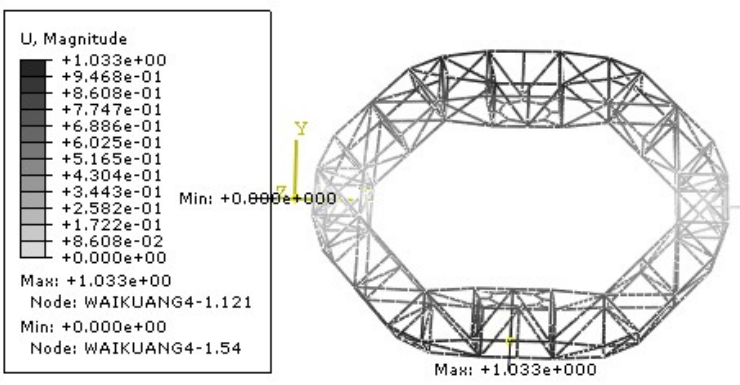

(a)

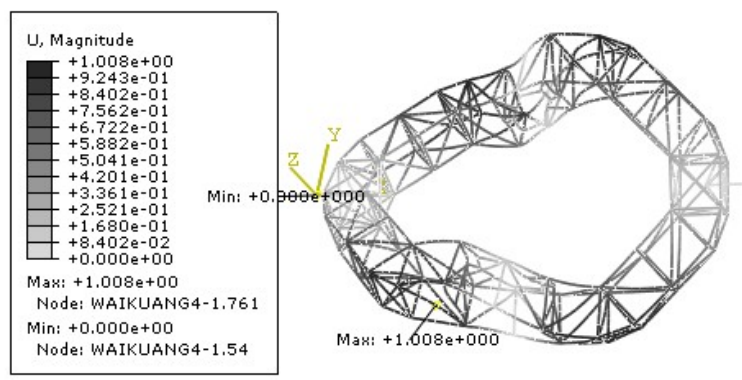

(c)

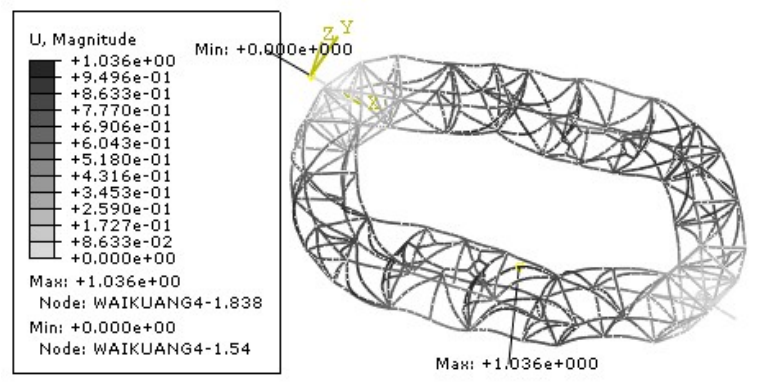

(e)

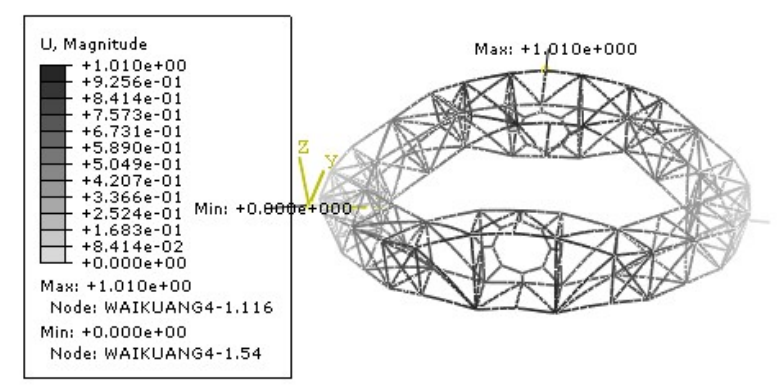

(b)

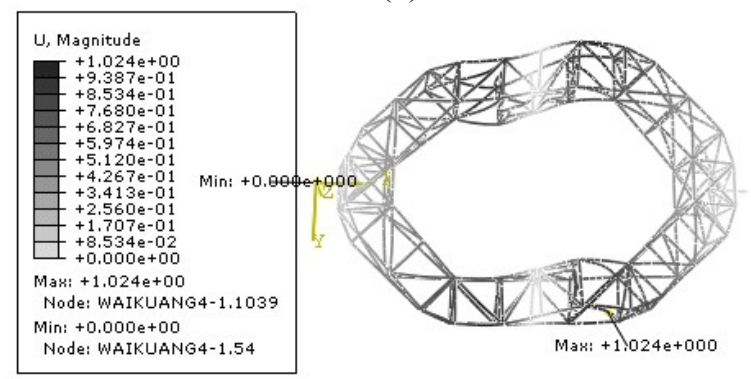

(d)

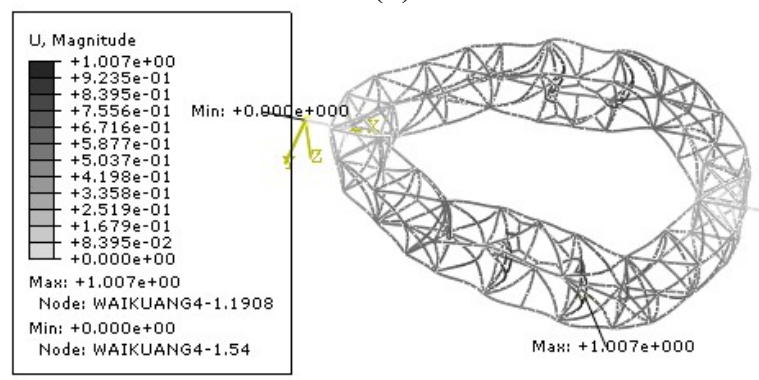

(f)

Figure 8, a)turntable's first vibration mode diagram b) turntable's second vibration mode diagram c) turntable's third vibration mode diagram d) turntable's fourth vibration mode diagram e)turntable's fifth vibration mode diagram f) turntable's sixth vibration mode diagram

Table 1 turntable frame before order natural frequency and vibration characteristics

\begin{tabular}{|c|c|l|}
\hline Order & $\begin{array}{c}\text { Natural frequency } \\
/ \mathrm{Hz}\end{array}$ & \multicolumn{1}{c|}{ Modal features } \\
\hline 1 & 1.6335 & The frame on both sides along the $\mathrm{X}$ positive direction distortion \\
\hline 2 & 10.381 & The frame on both sides along the $\mathrm{Z}$ positive direction bending \\
\hline
\end{tabular}




\begin{tabular}{|l|l|l|}
\hline 3 & 13.295 & The frame on both sides along the Z direction wave deformation \\
\hline 4 & 16.945 & The frame on both sides along the Z direction wave deformation \\
\hline 5 & 21.791 & $\begin{array}{l}\text { Each sides of frame along the positive and negative directions of the } \mathrm{X} \\
\text { bending }\end{array}$ \\
\hline 6 & 23.498 & The frame on both sides along the X positive direction bending \\
\hline
\end{tabular}

Turntable frame excitation frequency of $0.056 \mathrm{~Hz}$, and it are far away from the natural frequency of the turntable, so the turntable don't occur resonance.

\section{Conclusion}

1) We can see the static solution results of fuel system ground test simulation turntable, the stress are less than $230 \mathrm{MPa}$, which is less than the turntable material allowable stress.

2) We can see from the turntable frame modal analysis results, the turntable frame in case of no-load, vibration mode for bending along a certain direction and wave bending, the maximum amplitude of the frequency of $21.791 \mathrm{~Hz}$, the amplitude of $1.036 \mathrm{~mm}$. The maximum amplitude in the turntable's middle position.

3) Although the transfer structure to meet the static and modal design requirements, but the static analysis of the results shows that the turntable frame some of the rod low structural strength, by increasing The cross-section of these rods to increase its strength.

\section{References}

[1] Dong Song,Jianmin Zhou,Yanwen Wang. Model-based jet fuel system failure diagnosis system design and implementation[J].Measurement and Control Technology,2011,4(30):43 50(in Chinese)

[2] Yun Liu,Limen Xu. Fuel test rig manufacturing and installation [J]. Hongdu Technology,1990, 04:07 16(in Chinese)

[3] Yanyan Wu,Tieguo Luo,Fang Guo,Jie Huang.Research of Turntable Control System in Helicopter Fuel System Ground Simulation Test Rig.2010,01:34 39(in Chinese)

[4] Yong Zhang, Xiuyun Meng, Zhongwu Li.A Flying Simulation Table Modeling and Analysis [J]. The National System Simulation Technology and Application Symposium, 2001,01 (83): 62 68(in Chinese)

[5] Information on Abaqus/CAE User's Manual. 